Cite this: J. Mater. Chem. A, 2013, 1, 13484

Received 22nd July 2013

Accepted 1st September 2013

DOI: $10.1039 / c 3 t a 12826 a$

www.rsc.org/MaterialsA

\section{Mesoporous graphene paper immobilised sulfur as a flexible electrode for lithium-sulfur batteries $\uparrow$}

\author{
Xiaodan Huang, Bing Sun, Kefei Li, Shuangqiang Chen and Guoxiu Wang* \\ Free-standing flexible mesoporous graphene-sulfur nanocomposite electrodes have been prepared by a \\ sulfur vapor treatment approach. Amorphous sulfur homogeneously was distributed in the mesoporous \\ architectures of porous graphene paper, in which sulfur was immobilized. The as-prepared mesoporous \\ graphene-sulfur papers can be directly applied as electrodes in lithium-sulfur batteries without using a \\ binder, conductive additives or an extra current collector. The conductive flexible porous graphene \\ networks can effectively facilitate electron transfer and electrolyte diffusion. The free-standing sulfur- \\ graphene nanocomposite electrodes achieved a high discharge capacity of $1393 \mathrm{~mA} \mathrm{~h} \mathrm{~g}{ }^{-1}$ with an \\ enhanced cycling stability and good rate performance.
}

\section{Introduction}

Due to severe energy and environmental issues, the development of high performance energy storage and conversion systems has become highly desirable. ${ }^{1-7}$ Among the current candidates, the rechargeable lithium battery is widely recognized as one of the best choices. ${ }^{\mathbf{1 , 2 , 4}}$ Lithium-ion batteries are dominant power sources for portable electronic devices., ${ }^{2,4}$ However, the performance of lithium-ion batteries remains insufficient for high-power applications, such as electrical vehicles and stationary electricity storage, owing to the relatively low capacity of the cathode materials., ${ }^{2,3,5,7}$ Recently, a rechargeable lithium-sulfur battery has attracted great attention, because elemental sulfur (S) has an ultrahigh theoretical capacity of $1675 \mathrm{~mA} \mathrm{~g}^{-1}$ with a specific energy density of $2600 \mathrm{~W}$ $\mathrm{h} \mathrm{kg}^{-1} \cdot{ }^{2,3,5,7}$ Sulfur also has many other advantages, including low cost, natural abundance and non-toxicity. ${ }^{8}$ However, the practical application of the Li-S battery has not yet been realised. The main obstacles include the low electrical conductivity of sulfur $\left(5 \times 10^{-30} \mathrm{~S} \mathrm{~cm}^{-1}\right)$, the dissolution of soluble polysulfides in the electrolyte, and the large volume change (80\%) during lithiation-delithiation cycles, which can cause a low sulfur utilization efficiency and limited cycling stability., Extensive efforts have been carried out to address the current challenges in Li-S batteries. Carbon materials, such as carbon nanotubes/nanofibers, ${ }^{\mathbf{9}, 10}$ porous carbon, ${ }^{3,11-19}$ hollow carbon

Centre for Clean Energy Technology, School of Chemistry and Forensic Science, University of Technology Sydney, NSW 2007, Australia. E-mail: Guoxiu.Wang@uts. edu.au

$\dagger$ Electronic supplementary information (ESI) available: TEM images of MGP and MGP-S, TEM and SEM element mapping of MGP-S, TGA and electrochemical results of intermediate sample, Coulombic efficiency of MGP-S. See DOI: 10.1039/c3ta12826a spheres, ${ }^{15,16}$ and graphene $e^{5,20-23}$ have been widely used to immobilise $\mathrm{S}$, in order to enhance the electrical conductivity and prevent the dissolution of polysulfides. Among all of these carbon materials, graphene has attracted special interest, due to its high electrical conductivity, strong mechanical property and good chemical stability.

The assembly of graphene sheets into three-dimensional (3D) porous structures can combine the excellent properties of graphene and the advantages of $3 \mathrm{D}$ porous architectures. ${ }^{\mathbf{2 4 - 2 9}}$ When applied in lithium-ion batteries and supercapacitors, porous graphene materials can serve as a highly-conductive flexible matrix to accommodate active materials (metal, metal oxides and polymers) and achieve significantly improved electrochemical performances..$^{\mathbf{2 4 , 2 8 , 3 0 - 3 2}}$ For example, 3D macroporous- $\mathrm{MnO}_{2}$ composites showed a much higher specific capacitance and a better rate retention than pristine graphene$\mathrm{MnO}_{2}$ composites in supercapacitor applications. ${ }^{30}$ Thermal expansion-generated hierarchical porous graphene ${ }^{33}$ and chemically activated nanoporous graphene ${ }^{34}$ have been employed as $\mathrm{S}$ confinement scaffolds to improve the electrochemical performances.

Since the first discovery, mesoporous carbon materials have attracted substantial interest because of their interesting properties such as ordered mesopores, high surface area, large pore volume and good conductivity. ${ }^{35-37}$ The morphology control of mesoporous carbon is an important factor for practical applications. Considering the texture of batteries, the freestanding flexible film or paper morphology could be ideal for electrode applications, without the need to use binders and additives. In this paper, mesoporous graphene paper (MGP) is employed to immobilize elemental sulfur as free-standing electrodes for high performance Li-S batteries. 


\section{Experimental section}

\section{Preparation of graphene oxide}

Graphite oxide was synthesized from graphite purchased from Sigma-Aldrich using a modified Hummers method. In a typical reaction, graphite $(0.5 \mathrm{~g}), \mathrm{NaNO}_{3}(0.5 \mathrm{~g})$, and $\mathrm{H}_{2} \mathrm{SO}_{4}(23 \mathrm{ml})$ were stirred in an ice bath. Then, $\mathrm{KMnO}_{4}(3 \mathrm{~g})$ was slowly added. After stirring for $30 \mathrm{~min}$, the mixture was transferred to a $35{ }^{\circ} \mathrm{C}$ oil bath and stirring continued for about $1 \mathrm{~h}$. Then, $\mathrm{H}_{2} \mathrm{O}(40 \mathrm{ml})$ was added, and the mixture was stirred for another $30 \mathrm{~min}$ while the temperature was raised to $90{ }^{\circ} \mathrm{C}$. Finally, $\mathrm{H}_{2} \mathrm{O}(100 \mathrm{ml})$ was added, followed by the slow addition of $3 \mathrm{ml}$ of $\mathrm{H}_{2} \mathrm{O}_{2}(30 \%)$. The final suspension was then filtered and washed with water to obtain graphite oxide. The as-synthesized graphite oxide was dispersed in distilled water, and sonicated for $2 \mathrm{~h}$ to form a homogeneous graphene oxide $/ \mathrm{H}_{2} \mathrm{O}$ suspension $\left(1.0 \mathrm{mg} \mathrm{ml}^{-1}\right)$.

\section{Preparation of MGP}

Hollow siliceous spheres (HSSs) were prepared by a previously reported method. ${ }^{29}$ Typically, Pluronic F108 (1.0 g) and 1,3,5-trimethylbenzene (TMB) $(1.0 \mathrm{~g})$ were mixed in a $\mathrm{HCl}$ solution $(2.0 \mathrm{M}, 30 \mathrm{ml})$ and kept stirring for $6 \mathrm{~h}$ at $25{ }^{\circ} \mathrm{C}$. Tetraethylorthosilicate (TEOS) (1.0 g) was added dropwise into the suspension under vigorous stirring. The whole system was allowed to react for $6 \mathrm{~h}$. Dimethoxydimethylsilane (DMDMS) $(0.5 \mathrm{~g})$ was added to the suspension and the reaction was continued for another $48 \mathrm{~h}$. The resulting mixture was dialyzed in distilled water for $48 \mathrm{~h}$. The dialyzed suspension was diluted to $60 \mathrm{ml}$ by distilled water to obtain a $\mathrm{HSSs} / \mathrm{H}_{2} \mathrm{O}$ solution. The graphene oxide suspension ( $600 \mathrm{ml}, 1.0 \mathrm{mg} \mathrm{ml}^{-1}$ ) was mixed in the $\mathrm{HSSs} / \mathrm{H}_{2} \mathrm{O}$ solution and the whole system was left to stir for $12 \mathrm{~h}$ at room temperature. Carbon nanofibers $(20 \mathrm{mg}$, SigmaAldrich 719811) were dispersed in $\mathrm{H}_{2} \mathrm{O}(400 \mathrm{ml})$ by the assistance of sodium dodecyl sulfate (SDS) $(1.0 \mathrm{~g})$. Then, the GO-template composite suspension $(50 \mathrm{ml})$ was mixed with the carbon nanofiber solution $(20 \mathrm{ml})$ for 10 seconds. The mixture was filtered to obtain a mesoporous paper. The dried sample was calcined at $350{ }^{\circ} \mathrm{C}$ for $5 \mathrm{~h}$ under an argon atmosphere. The sample was then washed with a $\mathrm{NaOH}$ aqueous solution $(4 \mathrm{M})$ at $90{ }^{\circ} \mathrm{C}$ three times to obtain the MGP.

\section{Preparation of MGP-S}

MGP (10 mg) and elemental S ( $2 \mathrm{~g}$ ) were sealed in a steel vessel $(\sim 20 \mathrm{ml})$ and heated at $300{ }^{\circ} \mathrm{C}$ for $12 \mathrm{~h}$. After that, the sample was transferred into an oven and heated at $155^{\circ} \mathrm{C}$ for another $2 \mathrm{~h}$. The whole procedure was repeated once more to obtain the final product, MGP-S.

\section{Characterization}

Transmission electron microscopy (TEM) analysis was conducted using a JEM-2100 transmission electron microscope operated at $200 \mathrm{kV}$. A nitrogen sorption measurement was carried out at $77 \mathrm{~K}$ with a Micromeritics 3Flex Surface Characterization Analyzer. The Brunauer-Emmett-Teller (BET) method was used to calculate the specific surface area. The pore size distribution was derived from the adsorption branch of the isotherm, using the
Broekhoff-de-Boer (BdB) method with a spherical pore model. The total pore volume was calculated from the adsorbed amount at a maximum relative pressure $P / P_{0}$. Scanning electron microscopy (SEM) observations were performed on a field emission scanning electron microscope (FESEM, Zeiss Supra 55VP). Wideangle X-ray diffraction (XRD) patterns were recorded on a Bruker D4 X-ray Diffractometer with Ni-filtered $\mathrm{Cu} \mathrm{K} \alpha$ radiation $(\lambda=1.54056 \AA)$ at a voltage of $40 \mathrm{kV}$ and a current of $40 \mathrm{~mA}$. The compositions of the MGP-S were determined by thermal gravimetric analysis (TGA) using an SDT 2960 simultaneous DTA/TGA analyser with a heating rate of $10{ }^{\circ} \mathrm{C} \mathrm{min}^{-1}$ from room temperature to $600{ }^{\circ} \mathrm{C}$ under a nitrogen atmosphere.

\section{Electrochemical measurement}

The electrochemical testing was carried out by a Neware battery tester at room temperature. The MGP-S samples were cut into $\sim 0.6 \times 0.6 \mathrm{~cm}^{2}$ and directly used as binder-free working electrodes. Lithium foil was used as the counter electrode. The electrolyte was $1 \mathrm{M}$ lithium bis(trifluoromethanesulfonyl)imide (LiTFSI) and $1 \mathrm{wt} \%$ lithium nitrate $\left(\mathrm{LiNO}_{3}\right)$ in 1,3-dioxolane and 1,2-dimethoxyethane (volume ratio $1: 1$ ). CR2032-type coin cells were fabricated in a glove box with an argon atmosphere. The charge-discharge cycles of the cells were measured in a voltage range of 1.0-3.0 V. The capacity was calculated based on sulfur. Cyclic voltammetry measurements were conducted on an electrochemistry workstation (CHI660D) at a scanning rate of $0.1 \mathrm{mV} \mathrm{s}^{-1}$ in a voltage window of $1-3.0 \mathrm{~V} v \mathrm{~s}$. a $\mathrm{Li}^{-\mathrm{Li}^{+}}$electrode.

\section{Results and discussion}

The vapor treatment approach to introduce $\mathrm{S}$ into a MGP porous architecture is schematically demonstrated in Fig. 1. At $300{ }^{\circ} \mathrm{C}$, elemental $\mathrm{S}$ is evaporated and diffuses into the internal pores of the MGP to achieve a homogeneous immobilization. Fig. 2 shows a digital photograph of the mesoporous paper with a freestanding and flexible nature. As shown in Fig. 2b, the asprepared MGP paper is highly flexible. To reveal the internal nanostructure, TEM characterization of the MGP material was carried out (Fig. 3a). A highly porous nanostructure can be clearly observed, along with the carbon nanofibers (Fig. S1a $\dagger$ ) which bridges the porous graphene sheet into an intact freestanding film. The pores shown in Fig. 3a display a relatively uniform diameter below $50 \mathrm{~nm}$, clearly falling in the mesoporous range $(2-50 \mathrm{~nm})$. From Fig. 3a, the thin layer pore walls can be identified, revealing that the porous architecture is constructed by graphene nanosheets. Estimated from the crosssection SEM image (Fig. S2 $\dagger$ ), the thickness of the MGP was determined to be around $10 \mu \mathrm{m}$. The $\mathrm{N}_{2}$ adsorption-desorption curves of the MGP sample (Fig. 4a) show a type IV isotherm with a steep increase of nitrogen absorption at a high relative pressure $\left(P / P_{0}=0.80-0.99\right)$, indicating that the major pore volume is contributed to by large size pores. Calculated by the BdB spherical pore model, the majority of the pore sizes are narrowly distributed at $31.6 \mathrm{~nm}$ (Fig. 4b), well matched with the TEM observation result. Originated from the highly porous structure, the MGP sample exhibits a high specific surface area of 

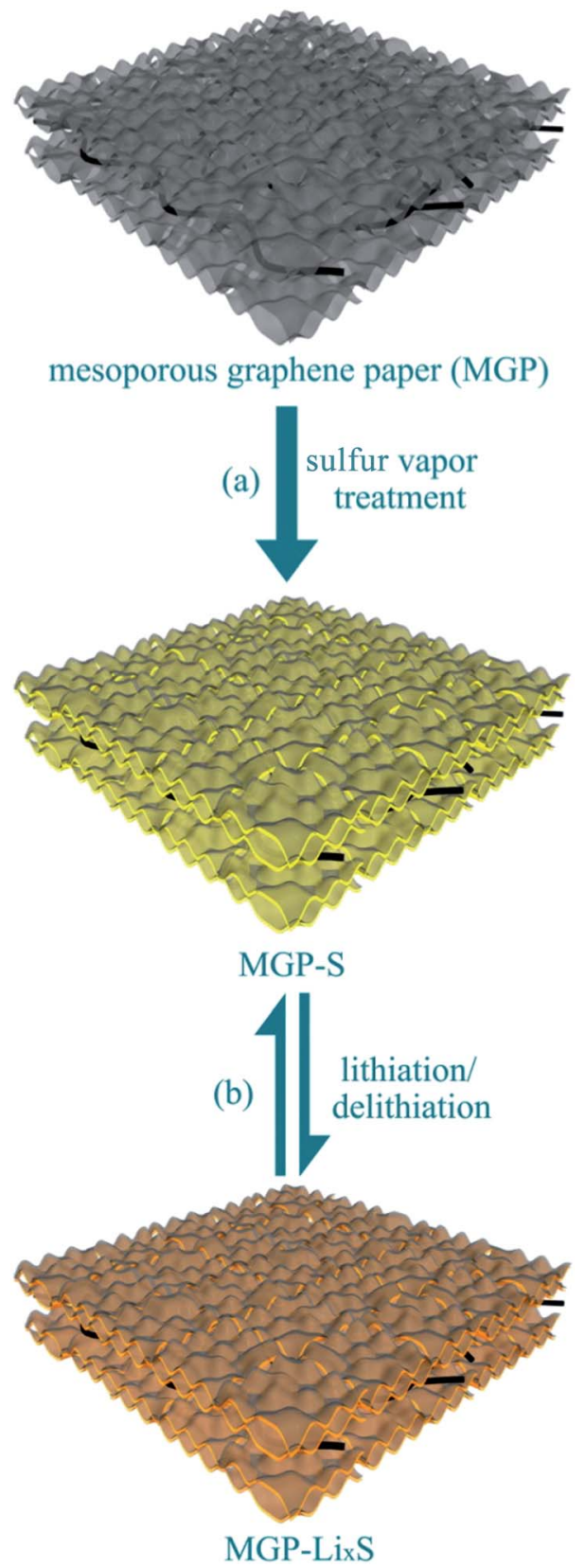

Fig. 1 A schematic illustration for the preparation of mesoporous graphene paper-sulfur electrodes and application as cathode in lithium-sulfur batteries.

$524.8 \mathrm{~m}^{2} \mathrm{~g}^{-1}$ and a large pore volume of $\sim 1.25 \mathrm{~cm}^{3} \mathrm{~g}^{-1}$. After $\mathrm{S}$ vapor treatment, the pores of the MGP were filled with sulfur. Fig. $3 \mathrm{~b}$ and $\mathrm{S} 1 \mathrm{~b} \uparrow$ show that the original empty pores have been loaded with a similar contrast component, implying the successful introduction of $\mathrm{S}$. As revealed by the $\mathrm{N}_{2}$-sorption analysis (Fig. 4), the total $\mathrm{N}_{2}$ adsorption amount and the mesoporous volume of the MGP-S sample decreases significantly, further confirming that $\mathrm{S}$ was entrapped in the pores of the MGP material.

Fig. 5a shows the wide-angle XRD patterns of the bulk $\mathrm{S}$ and MGP-S sample. The well-resolved diffraction peaks corresponding to face-centered orthorhombic $\mathrm{S}$ crystalline (JCPDS 08-0247) totally disappear after the impregnation of S into the

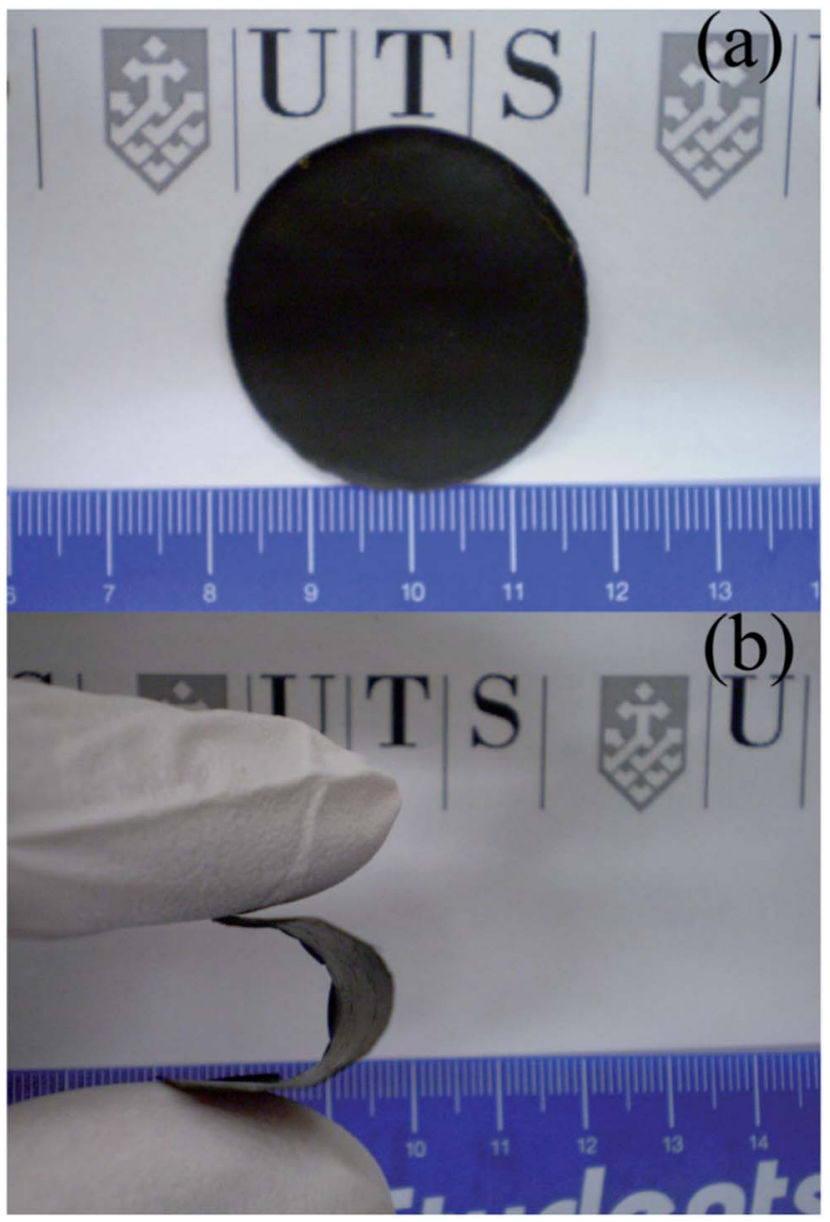

Fig. 2 Digital photographs of the MGP paper, exhibiting an intact paper-like morphology (a) and flexible property (b).

MGP. Only a broad peak located at $\sim 26^{\circ}$ is identified in the XRD pattern of the MGP-S, which can be ascribed to the graphene sheet pore walls. ${ }^{38}$ The wide-angle XRD result demonstrates that the vapor treatment approach can completely convert bulk S, to amorphous form, into porous architectures. To quantify the content of graphene and sulfur in the nanocomposites, TGA was carried out in a nitrogen atmosphere, with a heating rate of $10^{\circ} \mathrm{C} \mathrm{min}{ }^{-1}$ from room temperature to $600{ }^{\circ} \mathrm{C}$. The TGA curve of the MGP-S is presented in Fig. $5 \mathrm{~b}$ along with the plots of the MGP and bulk S. The pristine MGP exhibits a good thermal stability, only showing a very slight weight loss (Fig. 5b, A). The evaporation of pure $\mathrm{S}$ occurs at a narrow temperature range of 120-300 ${ }^{\circ} \mathrm{C}$ (Fig. 5b, C). The weight loss of the MGP-S sample (Fig. 5b, B) starts at about $180{ }^{\circ} \mathrm{C}$, a bit higher than that in the pure $\mathrm{S}$ plot. Moreover, a continuous weight loss profile is observed until $530{ }^{\circ} \mathrm{C}$ in the case of the MGP-S. The broadened decomposition temperature range should be ascribed to the graphene skeleton mesoporous structures. ${ }^{39,40}$ For the sulfur encapsulated in the mesopores, the evaporation of molecules is difficult, thus higher temperatures are required to volatilize the sulfur $\left(530{ }^{\circ} \mathrm{C}\right.$ for the MGP-S).${ }^{40}$ Calculated from the total weight loss, the sulfur content in the MGP-S sample has been determined to be $55 \%$. The $S$ vapour treatment was conducted twice 


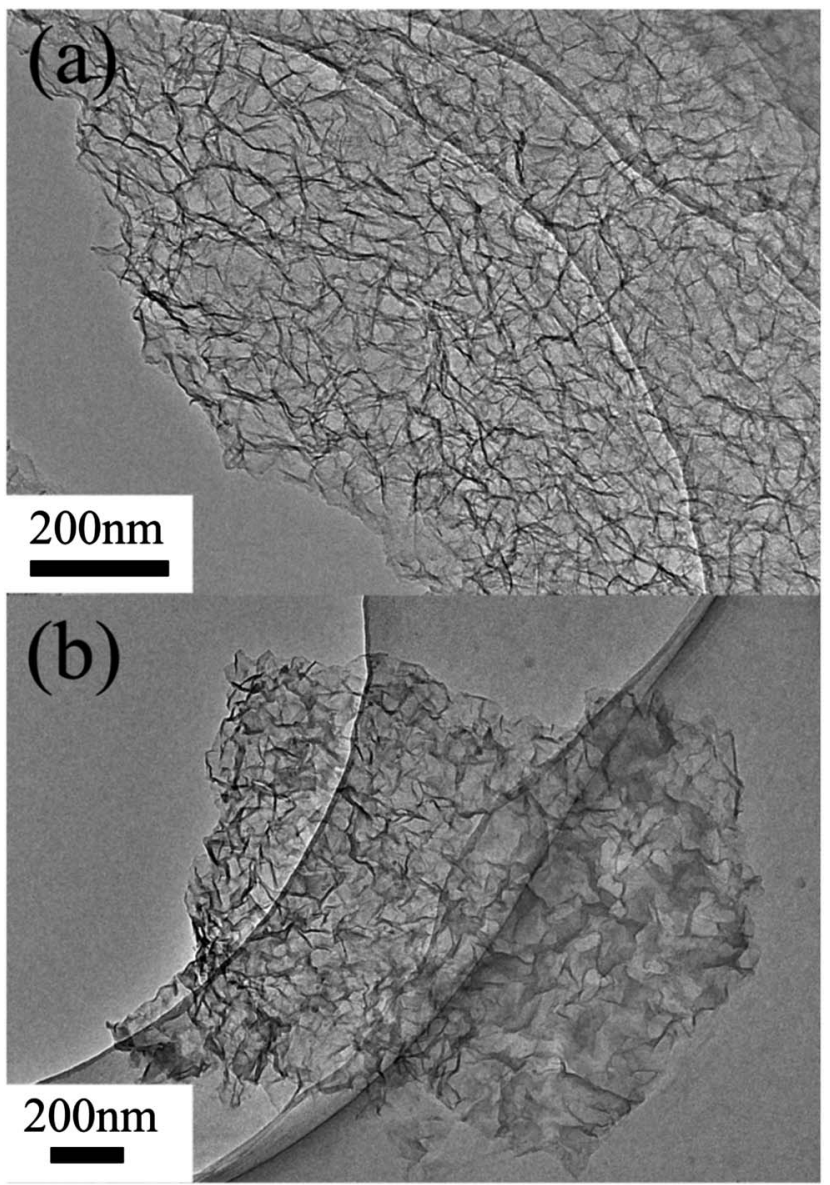

Fig. 3 (a) TEM image of MGP. (b) TEM image of MGP-S

to achieve the full utilization of the mesopores in the MGP, which is reflected by the $\mathrm{N}_{2}$-sorption results (Fig. 4). When the MGP material was S vapour treated once, only $29 \%$ sulfur was loaded (Fig. S3a†).

To demonstrate the homogeneous amorphous $\mathrm{S}$ distribution, TEM selected area electron diffraction (SAED) and element mapping were performed. Fig. $\mathrm{S} 4 \uparrow$ shows the analysis results. For a cracked MGP-S sample, only a light SAED ring, corresponding to the (002) planes of graphene sheets, can be detected, indicating the amorphous nature of the $\mathrm{S}$ anchored in the mesoporous graphene. In the carbon and sulfur element mapping images, $S$ signals spread throughout the entire TEM view of the sample, confirming that the well-dispersed amorphous $\mathrm{S}$ has been successfully introduced into the MGP mesoporous architectures through the vapor treatment approach. A large scale SEM elemental analysis results of the bulk MGP-S (Fig. S5 $\dagger$ ) also proved the uniform distribution of $\mathrm{S}$ in the MGP matrix.

Cyclic voltammetry (CV) tests were conducted to depict the electrochemical behaviours of the MGP-S and bulk $\mathrm{S}$ electrodes (Fig. S6†). The broad cathodic peak located at $1.7-2.3 \mathrm{~V}$ in the first CV cycle of the MGP-S electrode (Fig. S6a†) corresponds to the reduction of amorphous $\mathrm{S}$ to lithium polysulfides and lithium sulfides. In the subsequent scanning cycles, the cathodic peaks become more distinguished, indicating a deep discharge process and a more effective utilization of the
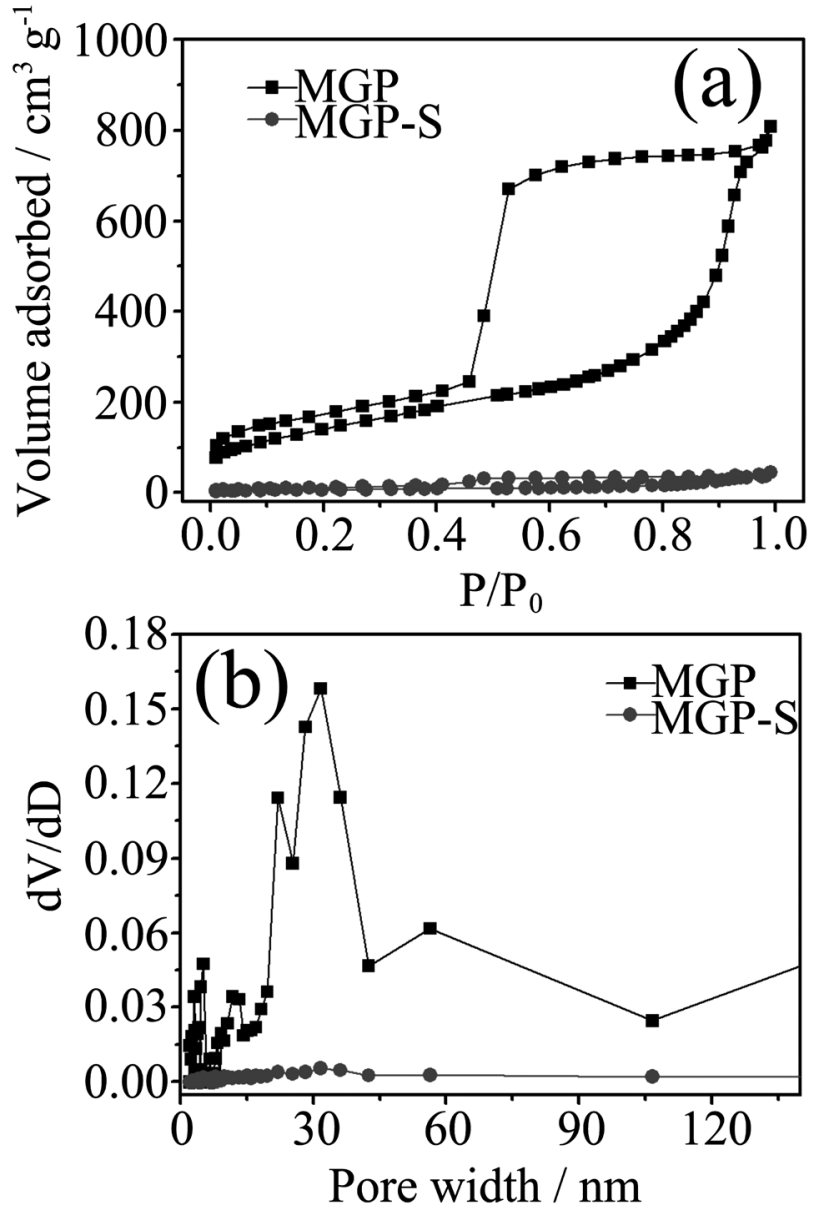

Fig. 4 (a) $N_{2}$-sorption isotherms of MGP and MGP-S. (b) The pore size distribution plots of MGP and MGP-S.

elemental sulfur. ${ }^{25}$ The anodic peaks of the MGP-S sample can be found at around $2.5 \mathrm{~V}$, representing the conversion of sulfides to elemental sulfur. However, the bulk $\mathrm{S}$ electrode gives a dramatically different CV curve (Fig. S6b $\dagger$ ). The cathodic peaks clearly shifted to a lower potential range and the anodic peaks moved to a higher potential area, indicating the severe polarizations caused by the poor conductivity of pure $\mathrm{S}$.

The electrochemical performance of the MGP-S was measured by directly applying the paper-like sample as an electrode in a $\mathrm{Li}^{-}$ $\mathrm{S}$ battery. Bulk $\mathrm{S}$ powders were also tested as a comparison. Fig. 6a displays the charge-discharge profiles of the MGP-S sample and bulk sulfur electrodes in the first cycle at $0.1 \mathrm{C}(1 \mathrm{C}=$ $1675 \mathrm{~mA} \mathrm{~g}^{-1}$ ). A main discharge plateau can be easily distinguished in the voltage ranges of and 2.1-1.5 V, corresponding to the conversion process of polysulfides to sulfides. Compared to the pure S sample, the discharge plateau of the MGP-S sustains much longer, implying a more efficient utilization of S. The initial discharge capacity of the MGP-S material can reach $1393 \mathrm{~mA} \mathrm{~h}$ $\mathrm{g}^{-1}$, which is much higher than the $371 \mathrm{~mA} \mathrm{~h} \mathrm{~g}^{-1}$ of pure $\mathrm{S}$. Furthermore, the subsequent charge profile of the MGP-S exhibits a good alleviation of the dissolution of S. The MGP-S sample cathode achieved a charging capacity of $1288 \mathrm{~mA} \mathrm{~h} \mathrm{~g}^{-1}$ with a Coulombic efficiency of $92.5 \%$. Therefore, a mesoporous 

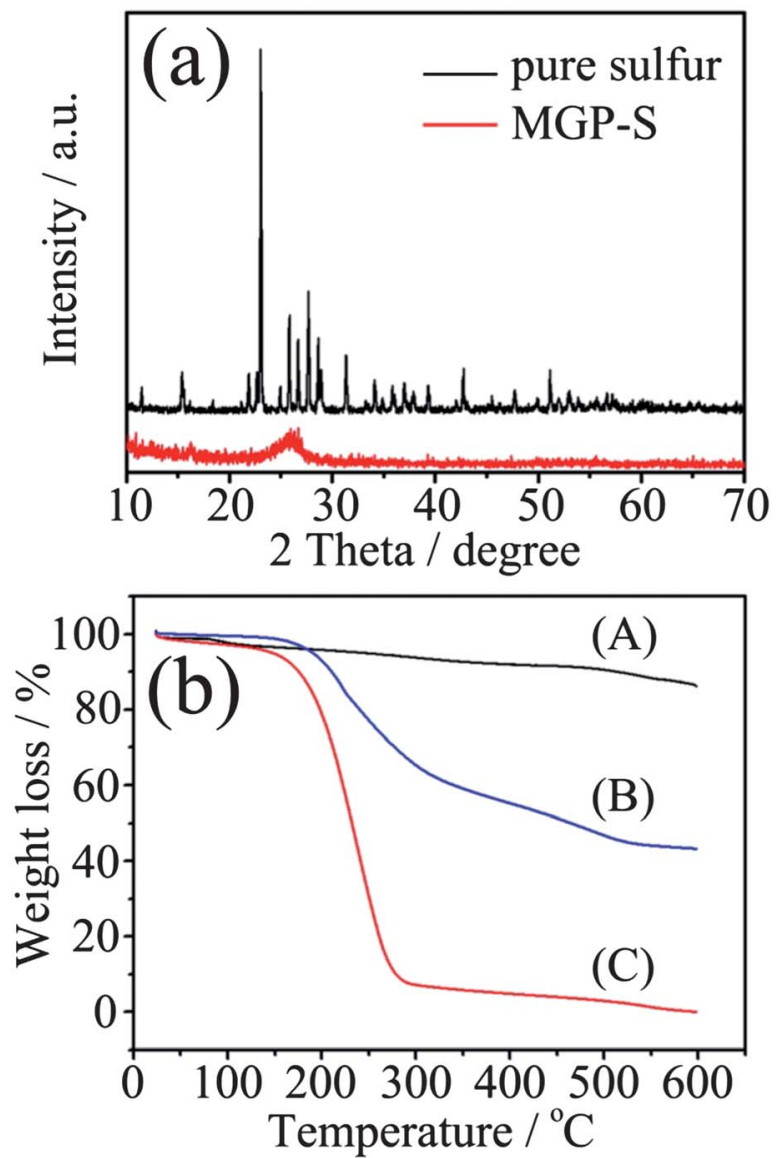

Fig. 5 (a) Wide-angle XRD patterns of pristine $S(A)$ and the MGP-S (B). (b) TGA curves of the MGP (A), MGP-S (B) and pristine $S(C)$.

graphene architecture can confine $\mathrm{S}$ to prevent polysulfide dissolution, leading to a high Coulombic efficiency.

Fig. $6 \mathrm{~b}$ shows the cycling performances of the MGP-S and pure $\mathrm{S}$ electrodes. The MGP-S electrode delivered a high specific discharge capacity of $1393 \mathrm{~mA} \mathrm{~h} \mathrm{~g}^{-1}$ at $0.1 \mathrm{C}$ in the first cycle. Then, the capacity slightly decayed on cycling, but was maintained quite well over 50 cycles. A specific discharge capacity of $689 \mathrm{~mA} \mathrm{~h} \mathrm{~g}{ }^{-1}$ was retained in the $50^{\text {th }}$ cycle, along with a continuous high Coulombic efficiency above $90 \%$ (Fig. S7†). As a comparison, the cycling performance of the bulk sulfur sample is also presented in Fig. $6 \mathrm{~b}$, displaying a very poor cyclability. The enhanced cycling stability could be attributed to the facile mesoporous architecture of the MGP-S electrode. The continuously mesoporous flexible graphene networks can cushion the volume change of elemental $\mathrm{S}$ during cycling (Fig. 1). Meanwhile, the conductive mesoporous graphene frameworks also facilitate electron transfer and electrolyte diffusion. The electrochemical performance of the sample treated by $\mathrm{S}$ vapour once was also measured, which exhibited similar properties to the MGP-S material (Fig. S2 $\dagger$ ). This further confirmed the function of the mesoporous graphene framework. However, the low S content of this sample $(29 \%)$ is not suitable for practical applications.

The rate performance measurement of the MGP-S cathode was tested by step-wise current testing, which further
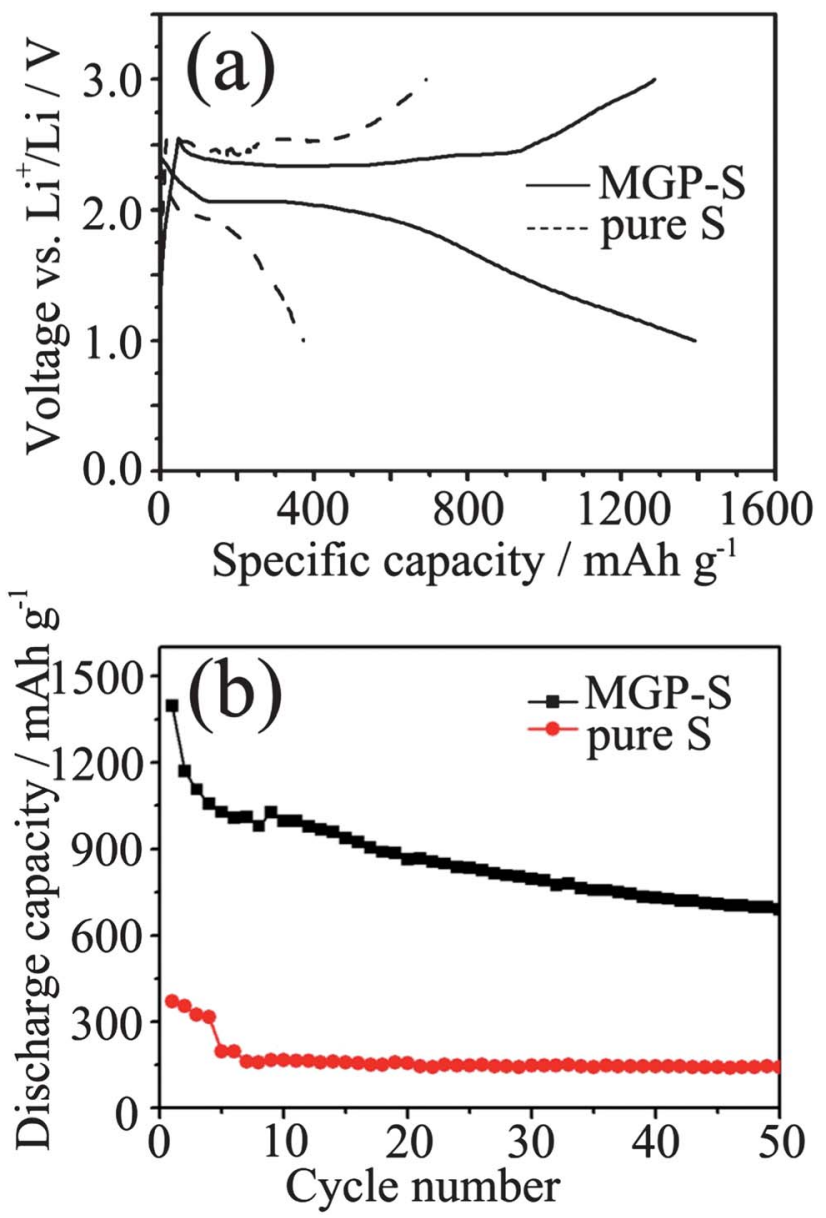

Fig. 6 Electrochemical performance of MGP-S electrodes. (a) The chargedischarge curves of the MGP-S and pure $S$ in the first cycles. (b) The cycling performance of the MGP-S and pure $S$ electrodes. The cells were cycled at $0.1 \mathrm{C}$.

demonstrated the superior electrochemical performance of the MGP-S nanocomposites (Fig. 7). At the high current densities of $1 \mathrm{C}$ and $3 \mathrm{C}$, the MGP-S electrode presented steady reversible capacities of 378 and $210 \mathrm{~mA} \mathrm{~h} \mathrm{~g}{ }^{-1}$, respectively. When the current density reversed back to $0.1 \mathrm{C}$, the electrode recovered the high discharge capacity. This result confirmed that the mesoporous graphene paper significantly enhanced the stability of the composite electrode, and therefore, improved the electrochemical performance of the battery. Considering the binder and additive free feature of the as-developed electrode, sulfur anchored mesoporous graphene paper could be directly applied as cathodes for lithium-sulfur batteries.

\section{Conclusions}

A vapor treatment approach to homogeneously introduce amorphous $\mathrm{S}$ into mesoporous graphene papers has been reported in this paper. The mesoporous graphene-sulfur nanocomposites have an intact free-standing flexible paper-like morphology. When directly applied as electrodes in lithiumsulfur batteries, the as-prepared material exhibits an enhanced electrochemical performance, including a high specific 


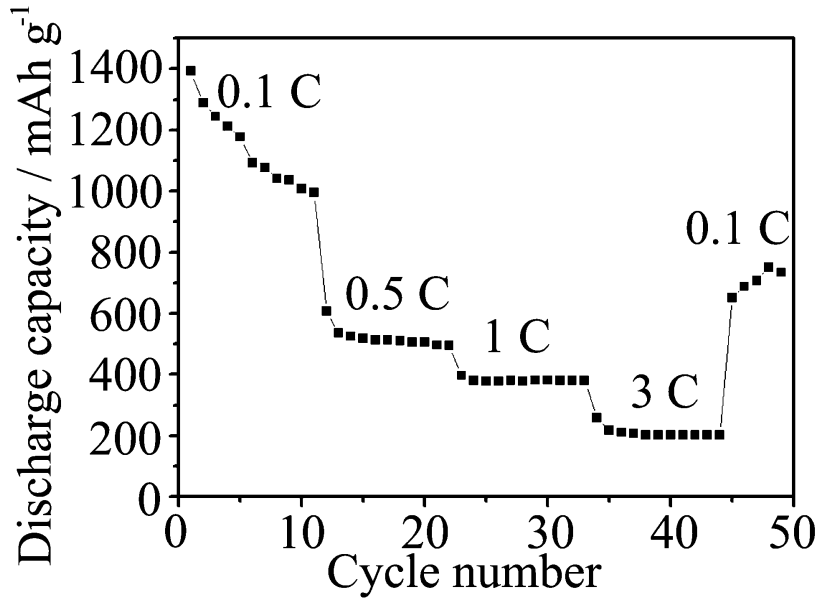

Fig. 7 The high rate capacities of MGP-S cathode.

discharge capacity of $1393 \mathrm{~mA} \mathrm{~h} \mathrm{~g} \mathrm{~g}^{-1}$, an improved cycling stability and a good rate performance.

\section{Acknowledgements}

This work was financially supported by the Australian Research Council (ARC) through the ARC Future Fellow project (FT110100800) and the ARC Discovery project (DP1093855).

\section{Notes and references}

1 M. Armand and J. M. Tarascon, Nature, 2008, 451, 652-657.

2 P. G. Bruce, S. A. Freunberger, L. J. Hardwick and J. M. Tarascon, Nat. Mater., 2012, 11, 19-29.

3 X. L. Ji, K. T. Lee and L. F. Nazar, Nat. Mater., 2009, 8, 500-506. 4 P. G. Bruce, B. Scrosati and J. M. Tarascon, Angew. Chem., Int. Ed., 2008, 47, 2930-2946.

5 H. L. Wang, Y. Yang, Y. Y. Liang, J. T. Robinson, Y. G. Li, A. Jackson, Y. Cui and H. J. Dai, Nano Lett., 2011, 11, 2644-2647.

6 G. Y. Zheng, Q. F. Zhang, J. J. Cha, Y. Yang, W. Y. Li, Z. W. Seh and Y. Cui, Nano Lett., 2013, 13, 1265-1270.

7 Z. W. Seh, W. Y. Li, J. J. Cha, G. Y. Zheng, Y. Yang, M. T. McDowell, P. C. Hsu and Y. Cui, Nat. Commun., 2013, 4, 1331.

8 K. F. Li, B. Wang, D. W. Su, J. Park, H. Ahn and G. X. Wang, J. Power Sources, 2012, 202, 389-393.

9 J. C. Guo, Y. H. Xu and C. S. Wang, Nano Lett., 2011, 11, 42884294.

10 G. Y. Zheng, Y. Yang, J. J. Cha, S. S. Hong and Y. Cui, Nano Lett., 2011, 11, 4462-4467.

11 J. Schuster, G. He, B. Mandlmeier, T. Yim, K. T. Lee, T. Bein and L. F. Nazar, Angew. Chem., Int. Ed., 2012, 51, 3591-3595.

12 C. D. Liang, N. J. Dudney and J. Y. Howe, Chem. Mater., 2009, 21, 4724-4730.

13 C. Lai, X. P. Gao, B. Zhang, T. Y. Yan and Z. Zhou, J. Phys. Chem. C, 2009, 113, 4712-4716.

14 B. Zhang, X. Qin, G. R. Li and X. P. Gao, Energy Environ. Sci., 2010, 3, 1531-1537.

15 N. Jayaprakash, J. Shen, S. S. Moganty, A. Corona and L. A. Archer, Angew. Chem., Int. Ed., 2011, 50, 5904-5908.
16 H. S. Ryu, J. W. Park, J. S. Park, J. P. Ahn, K. K. Kim, J. H. Ahn, T. H. Nam, G. X. Wang and H. J. Ahn, J. Mater. Chem. A, 2013, 1, 1573-1578.

17 H. Ye, Y. X. Yin, S. Xin and Y. G. Guo, J. Mater. Chem. A, 2013, 1, 6602-6608.

18 G. Y. Xu, B. Ding, L. F. Shen, P. Nie, J. P. Han and X. G. Zhang, J. Mater. Chem. A, 2013, 1, 4490-4496.

19 X. Y. Tao, X. R. Chen, Y. Xia, H. Huang, Y. P. Gan, R. Wu, F. Chen and W. K. Zhang, J. Mater. Chem. A, 2013, 1, 3295-3301.

20 Y. L. Cao, X. L. Li, I. A. Aksay, J. Lemmon, Z. M. Nie, Z. G. Yang and J. Liu, Phys. Chem. Chem. Phys., 2011, 13, 7660-7665.

21 L. W. Ji, M. M. Rao, H. M. Zheng, L. Zhang, Y. C. Li, W. H. Duan, J. H. Guo, E. J. Cairns and Y. G. Zhang, J. Am. Chem. Soc., 2011, 133, 18522-18525.

22 F. F. Zhang, X. B. Zhang, Y. H. Dong and L. M. Wang, J. Mater. Chem., 2012, 22, 11452-11454.

23 J. Z. Wang, L. Lu, M. Choucair, J. A. Stride, X. Xu and H. K. Liu, J. Power Sources, 2011, 196, 7030-7034.

24 S. Evers and L. F. Nazar, Chem. Commun., 2012, 48, 1233-1235. 25 B. Wang, K. F. Li, D. W. Su, H. J. Ahn and G. X. Wang, Chem.Asian J., 2012, 7, 1637-1643.

26 S. H. Lee, H. W. Kim, J. O. Hwang, W. J. Lee, J. Kwon, C. W. Bielawski, R. S. Ruoff and S. O. Kim, Angew. Chem., Int. Ed., 2010, 49, 10084-10088.

27 Z. P. Chen, W. C. Ren, L. B. Gao, B. L. Liu, S. F. Pei and H. M. Cheng, Nat. Mater., 2011, 10, 424-428.

28 S. Y. Yin, Y. Y. Zhang, J. H. Kong, C. J. Zou, C. M. Li, X. H. Lu, J. Ma, F. Y. C. Boey and X. D. Chen, ACS Nano, 2011, 5, 3831-3838. 29 X. D. Huang, K. Qian, J. Yang, J. Zhang, L. Li, C. Z. Yu and D. Y. Zhao, Adv. Mater., 2012, 24, 4419-4423.

30 B. G. Choi, M. Yang, W. H. Hong, J. W. Choi and Y. S. Huh, ACS Nano, 2012, 6, 4020-4028.

31 Z. S. Wu, Y. Sun, Y. Z. Tan, S. B. Yang, X. L. Feng and K. Mullen, J. Am. Chem. Soc., 2012, 134, 19532-19535.

32 N. Li, Z. P. Chen, W. C. Ren, F. Li and H. M. Cheng, Proc. Natl. Acad. Sci. U. S. A., 2012, 109, 17360-17365.

33 J. Q. Huang, X. F. Liu, Q. Zhang, C. M. Chen, M. Q. Zhao, S. M. Zhang, W. C. Zhu, W. Z. Qian and F. Wei, Nano Energy, 2013, 2, 314-321.

34 B. Ding, C. Z. Yuan, L. F. Shen, G. Y. Xu, P. Nie, Q. X. Lai and X. G. Zhang, J. Mater. Chem. A, 2013, 1, 1096-1101.

35 C. D. Liang, K. L. Hong, G. A. Guiochon, J. W. Mays and S. Dai, Angew. Chem., Int. Ed., 2004, 43, 5785-5789.

36 D. Feng, Y. Y. Lv, Z. X. Wu, Y. Q. Dou, L. Han, Z. K. Sun, Y. Y. Xia, G. F. Zheng and D. Y. Zhao, J. Am. Chem. Soc., 2011, 133, 15148-15156.

37 Y. Meng, D. Gu, F. Q. Zhang, Y. F. Shi, H. F. Yang, Z. Li, C. Z. Yu, B. Tu and D. Y. Zhao, Angew. Chem., Int. Ed., 2005, 44, 7053-7059.

38 G. M. Zhou, D. W. Wang, F. Li, L. L. Zhang, N. Li, Z. S. Wu, L. Wen, G. Q. Lu and H. M. Cheng, Chem. Mater., 2010, 22, 5306-5313.

39 H. Hermann, T. Schubert, W. Gruner and N. Mattern, Nanostruct. Mater., 1997, 8, 215-229.

40 X. D. Huang, L. Zhou, C. Z. Yu and D. Y. Zhao, J. Mater. Chem., 2012, 22, 11523-11528. 